\title{
ANALYSIS OF THE PARAMETRIC SENSITIVITY OF THE METHOD FOR OPTIMIZING THE STRUCTURE OF SPECTRALLY EFFECTIVE RADIO SIGNALS
}

DOI: $10.36724 / 2072-8735-202|-| 5-3-50-58$

Sergei S. Pechnikov,

Voronezh Institute of the Ministry of Internal

Affairs of Russia, Voronezh, Russia,

orl_os@mail.ru

Sergey A. Sherstyukov,

Voronezh Institute of the Ministry of Internal

Affairs of Russia, Voronezh, Russia,

sherstukov@vimvd.ru
Manuscript received 14 December 2020; Accepted 28 January 2021

Keywords: digital radio communication, signals with high spectral efficiency, linearization of power amplifiers, phase imbalance, constant envelope

\begin{abstract}
Currently, increasing the speed of information transmission in wireless communication networks is a topical issue. The growing demand for spectral efficiency in radio communication systems gives rise to the introduction of signals with amplitude-phase modulation. Despite all its advantages, signals with vector modulation are characterized by a change in the envelope, which makes it impossible to use highly efficient nonlinear power amplifiers. Energy efficiency is clearly a critical factor in portable radio communications systems, where power supplies are often used in small packages, and the presence of energy losses due to heat dissipation is a significant drawback that requires additional cooling systems. In this connection, when developing modern radio communications, radio engineers are faced with the contradictory task of achieving maximum energy and spectral efficiency. One of the approaches to reduce nonlinear distortion of vector modulation is the use linearization schemes for nonlinear power amplifiers. This work is devoted to increasing the energy and spectral efficiency of signals with amplitude-phase modulation. The article discusses the restrictions imposed on the input signals for the method for optimizing of structure of spectrally effective radio signals with vector modulation, the formation of the output signal, the influence of phase shifters phase imbalance on $\pi / 2$, the index of balance modulation, and the analysis of parametric sensitivity. The possibility of using quadrature modulators to form components with phase modulation and constant envelope is considered. This method was simulated and the effect of phase imbalance on the shape of the output signal constellation was revealed.
\end{abstract}

Information about authors:

Sergey S. Pechnikov, post-graduate cadet of Voronezh Institute of Russian Ministry of Internal Affairs, Voronezh, Russia

Sergey A. Sherstyukov, doctor of technical sciences, assistant professor, professor of the chair infocommunication systems and technologies at Voronezh Institute of the Ministry of Internal Affairs of Russia, Voronezh, Russia

\section{Для цитирования:}

Печников С.С., Шерстюков С.А. Анализ параметрической чувствительности способа оптимизации структуры спектрально-эффективных радиосигналов // T-Comm: Телекоммуникации и транспорт. 2021. Том 15. №3. С. 50-58.

For citation:

Pechnikov S.S., Sherstyukov S.A. (202I) Analysis of the parametric sensitivity of the method for optimizing the structure of spectrally effective radio signals. T-Comm, vol. I5, no.3, pp. 50-58. (in Russian) 


\section{Introduction}

Traditionally, the main requirement in the design of a narrowband RF power amplifier was to achieve the required output power in a given frequency range with the maximum values of energy efficiency. The level of development of digital information and telecommunication means simultaneously uses new technical and economic requirements: the width of the occupied frequencies, the transmission rate of messages, the spectral structure of the ensemble of the signals used, the information of the propagation of transmitted messages in a mixture with natural noise, and the linearity of the message transmission process to the communication line subscribers. Therefore, it is necessary to create new technical solutions to find a compromise in the set of criteria [1].

Currently, there is a need to transmit more and more information volumes, which leads to an increasingly dense placement of channels in the frequency range. In the conditions of a limited frequency resource, the problem of ensuring the electromagnetic compatibility of radio electronic equipment and increasing the spectral efficiency of transmitted signals becomes more acute. For these purposes, signals with amplitude-phase modulation are most suitable. However, their interaction with non-linear elements (primarily power amplifiers) leads to intermodulation distortion. If the intermodulation distortion of even orders lies outside the operating range and can be easily filtered out, then the intermodulation distortion of odd orders falls directly into the operating range of the device [2]. The only way to deal with them is to ensure the linearity of the amplifiers used, which is characterized by low efficiency. Thus, modern communications systems that use complex modulation schemes and generate a variable envelope output require high linearity power amplifiers. The purpose of this work is to consider the possibility of using a method for optimizing the structure of spectrally efficient radio signals with vector modulation for amplification in nonlinear power amplifiers, as well as to analyze the parametric sensitivity of this method.

\section{Constraints imposed on the input signals when applying the method for optimizing the structure of spectrally efficient radio signals}

Changing the envelope is a significant drawback of signals with amplitude-phase modulation. The possibility of using the method for optimizing the structure of spectrally efficient radio signals with vector modulation to obtain components with constant envelopes was considered earlier. It consists in creating algorithms for correlating the in-phase and quadrature components to minimize parasitic amplitude modulation in the resulting phase-modulated signals obtained [3]. Scheme of optimizing the structure of spectrally efficient radio signals is presented in Figure 1.

According to $[4,5]$, the index of phase modulation $m$, signals with constant envelope $u_{i}(t)$ and $u_{q}(t)$ will be determined by the instantaneous values of the amplitudes of the quadrature components of the input signal $Q(t)$ and $I(t)$.

Consider the constraints imposed on the signals $Q(t)$ and $I(t)$.

The synthesis process of functional converters of modulating voltage is based on the application of series theory and representation in the form of a Taylor series.

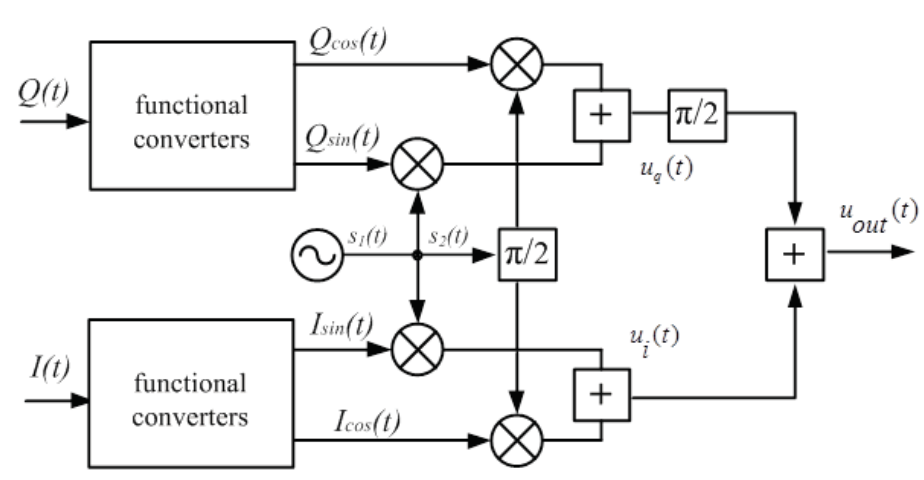

Figure 1. Scheme of optimization of the structure of spectrally effective radio signals

For function $f_{1}(x)=\sin x$

$$
f_{1}(x)=\frac{x}{1 !}-\frac{x^{3}}{3 !}+\frac{x^{5}}{5 !}-\cdots+(-1)^{n-1} \frac{x^{2 n-1}}{(2 n-1) !}+\cdots
$$

where $n=1,2,3, \ldots$ are the numbers of the members of the series.

In this case, the Lagrange remainder

$$
R_{2 n}(x)=\frac{\sin \left[\theta x+(2 n-1) \frac{\pi}{2}\right]}{(2 n+1) !} x^{(2 n+1)},
$$

and the error is estimated as follows:

$$
\left|R_{2 n}(x)\right| \leq \frac{|x|^{(2 n+1)}}{(2 n+1) !} .
$$

And for the function $f_{2}(x)=\cos x$ :

$$
f_{2}(x)=1-\frac{x^{2}}{2 !}+\frac{x^{4}}{4 !}-\cdots+(-1)^{n} \frac{x^{2 n}}{2 n !}+\cdots,
$$

where $n=0,1,2, \ldots$ are the numbers of the members of the series, including the zero row.

In this case, the Lagrange remainder

$$
R_{2 n+1}(x)=\frac{\cos \left[\theta x+(2 n+2) \frac{\pi}{2}\right]}{(2 n+2) !} x^{(2 n+2),}
$$

and the error is estimated as follows

$$
\left|R_{2 n+1}(x)\right| \leq \frac{|x|^{2 n+2}}{(2 n+2) !} .
$$

Expressions (1) and (4) are the initial ones for constructing functional transformers. If we bear in mind that the parameter $x$ included in these expressions is an analogue of the input signal for the synthesized structures, then actions on it will determine the corresponding functional transformations of the modulating signal (addition, inversion, multiplication), and the coefficients at $x$ - its attenuation. Thus, relying on the above expressions it becomes possible to implement the functional transformers in practice by changing the number of approximating terms of the expansion $n$ in expressions (1) and (4).

To analyze the residual error of the sine-cosine transformation, we set the argument of these functions $x=\pi$, then, from expression (3), the calculation error $\sin x$

$$
\left|R_{2 n}(x)\right| \leq \frac{\pi^{2 n+1}}{(2 n+1) !},
$$


and from expression (6), the calculation error $\cos x$

$$
\left|R_{2 n+1}(x)\right| \leq \frac{\pi^{2 n+2}}{(2 n+2) !}
$$

As can be seen from expressions (7) and (8), the limiting error tends to zero with increasing $n$. Argument $|x|$ is the amplitude of the instantaneous value of the input signal, in other words, it is equivalent to the phase modulation index $m_{\varphi}[3,4]$.

Thus, by increasing the number of approximating terms $n$, one can achieve ideal values of the sine and cosine functions for any values of the input signal (modulation depth). At the same time, an increase in the phase modulation index more than $m_{\varphi}>\pi / 4$ leads to a significant increase in the width of the output signal spectrum.

To increase the spectral efficiency, it is necessary to restrict oneself to the phase modulation index $m_{\varphi}<\pi / 4$, which allows, according to $[3,4]$, are restricted to 3 terms when approximating and constructing functional transducers with an error of $<1 \%$.

Formation of the output signal in the method of optimizing the structure of spectrally efficient radio signals.

When generating the output signal in the method for optimizing the structure of signals with vector modulation according to [6], $u_{i}(t)$ and $u_{q}(t)$ are phase modulation signals with a constant envelope

$u_{i}(t)=A(\cos \omega t \cos [i(t)]-\sin \omega t \sin [i(t)])=$

$=A \cos (\omega t+i(t))$,

$u_{q}(t)=A(\cos \omega t \cos [q(t)]-\sin \omega t \sin [q(t)])=$

$=A \cos (\omega t+q(t))$,

where the phase values $q(t)$ and $i(t)$ will be determined by the instantaneous values of the amplitudes of the quadrature components of the input signal.

When combining phase modulation signals, it is necessary to represent them in the form of in-phase and quadrature components of the output signal, therefore, we will shift one of the components by $\pi / 2$ to carry out further demodulation using a quadrature demodulator:

$u_{\text {out }}(t)=u_{i}(t)+j u_{q}(t)=A \cos (\omega t+i(t))+$

$+j A \cos (\omega t+q(t))=2 A \cos \left(\frac{(q(t)+\pi / 2)-i(t)}{2 a}\right) \times$

$\times \cos \left(\omega t+\frac{(q(t)+\pi / 2)+i(t)}{2 a}\right)$.

Another way to represent a vector modulated signal is to express it as the sum of two signals with the same amplitude and arbitrary phase $[7,8]$. The modulated signal $u_{\text {out }}(t)$ can be expressed graphically as shown in Figure 2. Vector with amplitude $A_{\text {out }}(t)$ and angle $\varphi_{\text {out }}(t)$ is the sum of two orthogonal vectors $u_{i}(t)$ and $u_{q}(t)$. In exponential form, the output signal can be written as:

$u_{\text {out }}(t)=\left[u_{i}(t)+j u_{q}(t)\right] e^{j \omega t}=$

$=2 A e^{j \omega t} e^{j[i(t)+q(t)+(\pi / 2)]}$.

In Figre 2, expressions (11) and (12) are presented in polar coordinates, where $u_{i}(t)$ and $u_{q}(t)$ are respectively orthogonal vectors with constant amplitude $A$ and phase states $\varphi_{1}$ and $\varphi_{2}$ for $i(t), \varphi_{3}$ and $\varphi_{4}$ for $q(t)$, while the phase modulation index of the vectors will be determined by the instantaneous values of the quadrature components of the input signal $Q(t)$ and $I(t)$. As a result of combining, a signal is formed with varying amplitude $A_{\text {out }}(t)$ and phase $\varphi_{\text {out }}$.

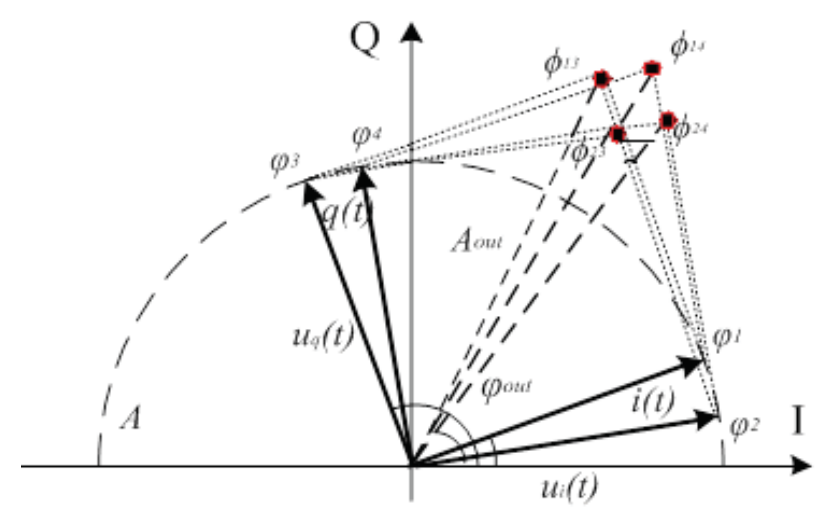

Figure 2. Formation of the output signal in polar coordinates

Figure 2 it can be seen that four states of the output phase values are possible. In two cases, the phase values are orthogonal, once more than $\pi / 2$ and once less than $\pi / 2$. The amplitude of the resulting oscillation is determined by the cosine theorem $A=\sqrt{A_{1}^{2}+A_{2}^{2}+A_{1} A_{2} \cos \left(\varphi_{2-} \varphi_{1}\right)}$, and the phase of the oscillation as

$$
\varphi_{\text {out }}=\operatorname{arctg}\left(\frac{A_{1} \sin \varphi_{1}+A_{2} \sin \varphi_{2}}{A_{1} \cos \varphi_{1}+A_{2} \cos \varphi_{2}}\right) .
$$

Then, for the case when the phase shift between vectors is $\Delta \varphi=\pi / 2$, then $A_{\text {out }}=\sqrt{2 A^{2}}, \varphi_{\text {out }}=\operatorname{arctg}(1)=\pi / 4$.

For a phase shift value $\pi / 2<\Delta \varphi$ and $\Delta \varphi<\pi / 2$,

$$
\begin{aligned}
& A_{\text {out }}=\sqrt{2 A^{2}+2 A^{2} \cos \left(\varphi_{q-} \varphi_{i}\right)}, \varphi_{\text {out }}= \\
& =\operatorname{arctg}\left(\frac{A \sin \varphi_{q}+A \sin \varphi_{i}}{A \cos \varphi_{q}+A \cos \varphi_{i}}\right) .
\end{aligned}
$$

In general, $i(t)$ and $q(t)$ are related to the amplitude and phase of the output signal, as

$$
\begin{gathered}
\varphi_{\text {out }}=[q(t) \pm i(t)] / 2, \\
A_{\text {out }}=2 A \cos [q(t) \pm i(t)] / 2 .
\end{gathered}
$$

Analysis of the parametric sensitivity of the method for optimizing the structure of spectral-efficient radio signals.

Let us consider the effect of phase imbalance when implementing a $\pi / 2$ phase shift in the carrier frequency path. Then expressions (9.10) take the form

$$
\begin{aligned}
& u_{i}(t)=S(\cos \omega t \cos [i(t)]-\sin [\omega t+\theta] \sin [i(t)], \\
& u_{q}(t)=S(\cos \omega t \cos [q(t)]-\sin [\omega t+\theta] \sin [q(t)] .
\end{aligned}
$$

where $S$ is the amplitude of the high-frequency signal $\theta$ is the phase imbalance of the phase shifter in the carrier frequency path. 
The vector diagram method allows you to simplify the addition of signals to the addition of vectors. We represent expressions (15) and (16) in the form $u(t)=U(t) \cos (\omega t+\varphi(t)$, then

$$
\begin{aligned}
& U_{i}=S \sqrt{\cos ^{2}[i(t)]+\sin ^{2}[i(\mathrm{t})]+2 \cos [i(\mathrm{t})] \sin [i(\mathrm{t})] \cos [\pi / 2+\theta]}= \\
& =S \sqrt{1-2 \cos [i(\mathrm{t})] \sin [i(\mathrm{t})] \sin [\theta]}
\end{aligned}
$$

$U_{q}=S \sqrt{\cos ^{2}[q(t)]+\sin ^{2}[q(\mathrm{t})]+2 \cos [q(\mathrm{t})] \sin [q(\mathrm{t})] \cos [\pi / 2+\theta]}=$ $=S \sqrt{1-2 \cos [q(\mathrm{t})] \sin [q(\mathrm{t})] \sin [\theta]}$

$$
\begin{aligned}
& \varphi_{i}=\operatorname{arctg}\left(\frac{\sin [i(\mathrm{t})] \sin [\pi / 2+\theta]}{\cos [i(\mathrm{t})]+\sin [i(t)] \cos [\pi / 2+\theta]}\right)= \\
& =\operatorname{arctg}\left(\frac{\sin [i(\mathrm{t})] \cos [\theta]}{\cos [i(\mathrm{t})]+\sin [i(t)] \sin [\theta]}\right) . \\
& \varphi_{q}=\operatorname{arctg}\left(\frac{\sin [q(\mathrm{t})] \sin [\pi / 2+\theta]}{\cos [q(\mathrm{t})]+\sin [q(t)] \cos [\pi / 2+\theta]}\right)= \\
& =\operatorname{arctg}\left(\frac{\sin [q(\mathrm{t})] \cos [\theta]}{\cos [q(\mathrm{t})]+\sin [q(t)] \sin [\theta]}\right)
\end{aligned}
$$

Considering expressions (17), (18) and (19), (20), we can conclude that when forming the quadrature components of the high-frequency oscillation, when $\theta=0$, the amplitudes of the phase-modulated components $A=S$, the phases $\varphi_{i}=i(t)$ and $\varphi_{q}=q(t)$, and the formation of phase-modulated components occurs without amplitude-phase distortions.

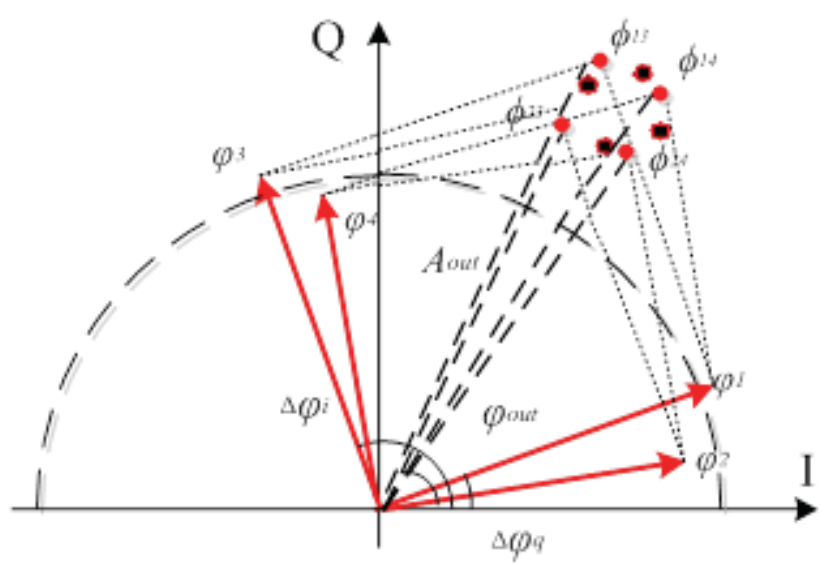

Figure 3. Influence of phase imbalance in the carrier frequency path on the formation of the output signal

Figure 3 shows in polar coordinates the change in the output signal constellation with an imbalance in the phase of the phase shifter in the carrier frequency path. You can observe the rotation of the phase points around the center of the output constellation and the appearance of parasitic amplitude modulation in the component vectors with phase modulation.

Thus, the occurrence of a phase imbalance during the implementation of the $\pi / 2$ phase shift in the carrier frequency path entails the parallel occurrence of parasitic amplitude modulation in both branches of the formed components with phase modulation $u_{i}(t)$ and $u_{q}(t)$, as well as the same phase shift.

Let us consider the influence of the phase imbalance during the implementation of the $\pi / 2$ phase shift in the tract of the formation of the quadrature FM component with a constant envelope.
The output signal is defined as:

$$
\begin{aligned}
& u_{\text {out }}(t)=u_{i}(t)+j u_{q}(t)=A \cos (\omega t+i(t))+ \\
& +j A \cos (\omega t+q(t)+\theta)=A \cos (\omega t+i(t))+ \\
& A \cos (\omega t+q(t)+\theta+\pi / 2)
\end{aligned}
$$

where $\theta$ is the phase shifter imbalance.

In exponential form, the output signal can be written as:

$u_{\text {out }}(t)=A e^{j(\omega t+i(t))}+A e^{j[\omega t+q(t)+(\pi / 2)+\theta]}$.

In Figure 4 in polar coordinates, you can observe the displacement of the signal constellation on the phase plane.

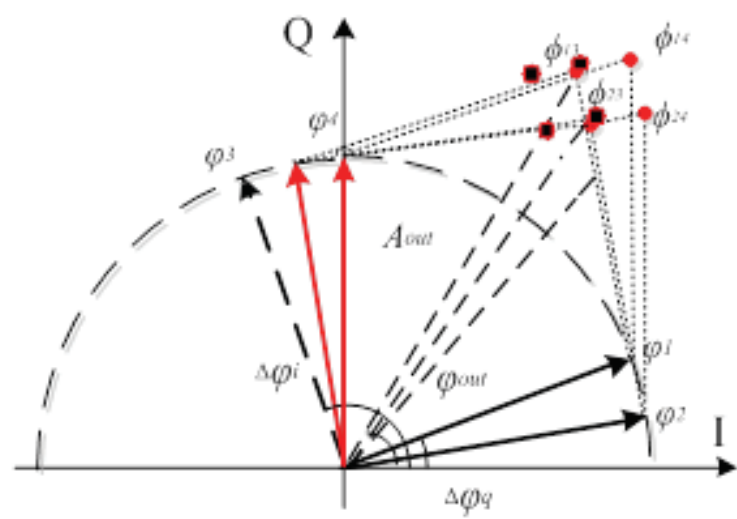

Figure 4. Influence of phase imbalance in the tract of the formation of the quadrature PM component on the formation of the output signal

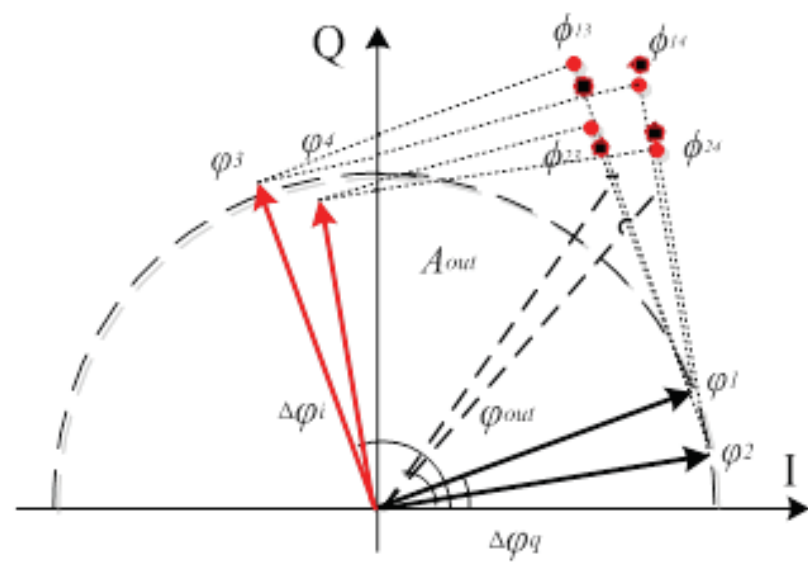

Figure 5. Influence of inaccuracy of the transfer coefficient of the balance modulator

Let us consider the influence of the inaccuracy of the transmission coefficients of balance modulators in the quadrature branches on the quality of the formation of PM signals.

$$
\begin{aligned}
& u_{i}(t)=S k_{\text {бм } 1} \cos \omega t \cos [i(t)]-S k_{\text {бм } 2} \sin \omega t \sin [i(t)] \\
& u_{q}(t)=S k_{\text {бм } 3} \cos \omega t \cos [q(t)]-S k_{\text {бм } 4} \sin \omega t \sin [q(t)]
\end{aligned}
$$

where $k_{b m}$ is the transfer coefficient of balanced modulators.

From expressions (23) and (24) it can be seen that at $k_{b m 1}=k_{b m 2}=k_{b m 3}=k_{b m 4}=1, A=S$, phase $\varphi_{i}=i(t)$ and $\varphi_{q}=q(t)$, and the formation of phase-modulated components occurs without amplitude phase distortion. 
The use of quadrature modulators for the formation of phase modulated components with a constant envelope.

Let us consider the possibility of using quadrature modulators to form the components with phase modulation $u_{i}(t)$ and $u_{q}(t)$, to separate the effect on the components of the phase shifter phase imbalance by $\pi / 2$ in the carrier frequency path.

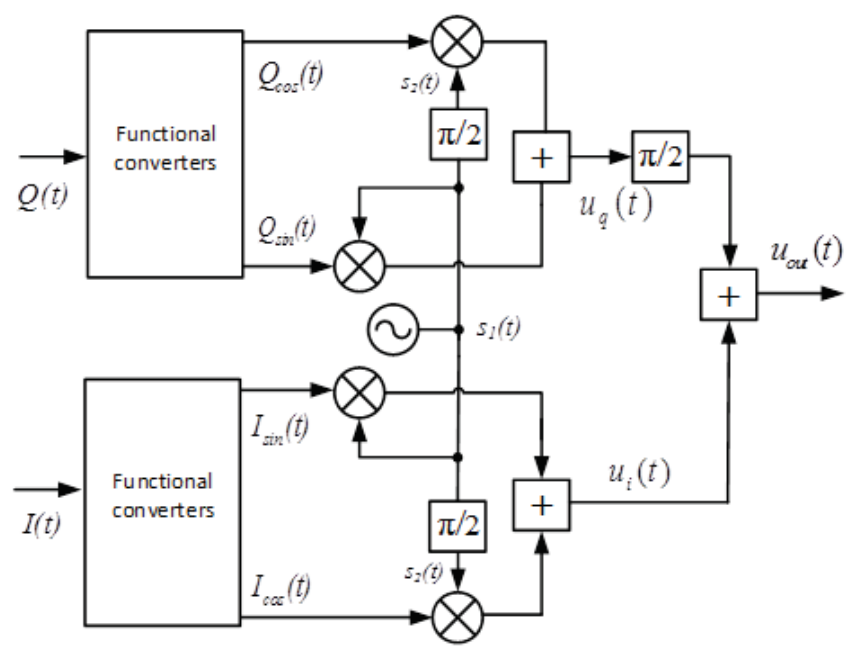

Figure 6. Implementation of the method for optimizing the structure of spectral-efficient radio signals using quadrature modulators

To do this, let's make changes to the circuit shown in Figure 1. Figure 6 shows a diagram in which, in contrast to Figure 1, another $\pi / 2$ phase shifter is introduced in the carrier frequency path. Thus, we get two independent quadrature modulators with a common source of high-frequency signal. The input signals for the first quadrature modulator are the functional components of the quadrature input signal, and for the second quadrature modulator the input signals are the functional components of the in-phase input signal. As a result, when the components with phase modulation and constant envelope are formed, the phase shift by $\pi / 2$ in the carrier frequency path occurs independently for each signal and the occurrence of phase imbalance in one of the quadrature modulators does not entail distortion and parasitic amplitude modulation in the parallel channel. In addition, the use of the already existing element base of quadrature modulators simplifies the process of technical implementation of the method for optimizing the structure of spectrally efficient radio signals.

$$
\begin{aligned}
& u_{\text {out }}(t)=A \cos (\omega t+i(t))+(S(\cos \omega t \cos [q(t)]- \\
& -\sin [\omega t+\theta] \sin [q(t)]),
\end{aligned}
$$

where $\theta$ is the phase imbalance of the phase shifter of the quadrature modulator forming the quadrature component with phase modulation.

In Figure 7 in polar coordinates shows the change in the output signal constellation with an imbalance in the phase of the phase shifter in one of the quadrature modulators.

One can observe the appearance of parasitic amplitude modulation in one of the components and the distortion of the output ensemble. As the imbalance increases, the constellation tends to a straight line.

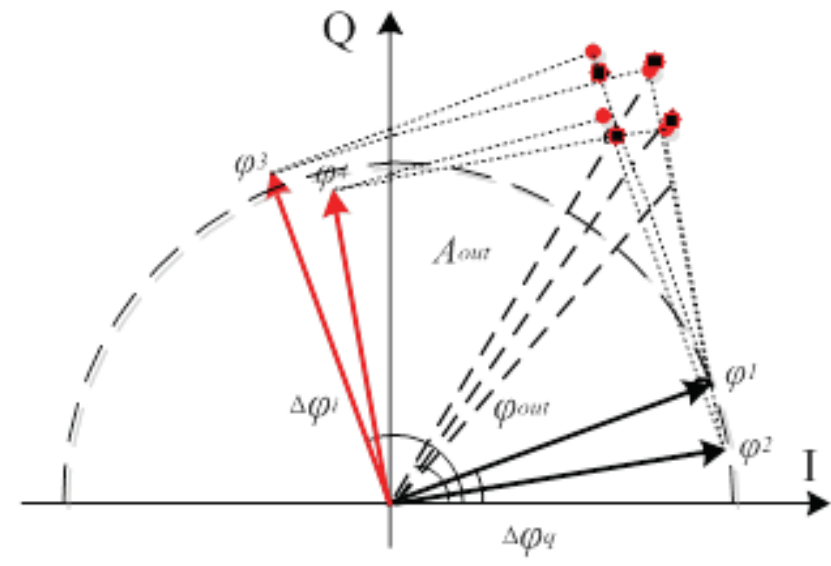

Figure 7. Influence of the phase imbalance of the quadrature modulator on the formation of the output signal

Modeling a method for optimizing the structure of spectrally efficient radio signals.

To analyze the parametric sensitivity of the method for optimizing the structure of vector modulation signals, let us carry out modeling in the computer-aided design system "Advanced Design System" [9].

As a spectrally efficient type of modulation, we will choose quadrature phase shift keying (QPSK), with a rate of $f_{b}=32$ kbit/s. QPSK has four different phase states that are generated by the serial bit to symbol conversion circuitry. These phase states are stored for a signaling interval $T_{s}$, which is equal to the duration of two bits $T_{s}=2 T_{b}$. The generated sequences with a symbol rate half the input bit stream rate are fed to filters with the "square root of the raised cosine" characteristic with a rounding factor $\alpha=0.5$, which minimizes intersymbol distortion and increases spectral efficiency [10].

As a result, at the output of the filter, we obtain the in-phase $I(t)$ and quadrature $Q(t)$ signal components, which are fed to the generators of the functional components. Consider two options for the formation of phase-modulated components with a constant envelope. In the first case, with the use of multipliers, adders and one phase shifter at $\pi / 2$ (Fig. 1), and in the second, with the use of quadrature modulators (Fig. 5). In both cases, the carrier frequency is $f_{C}=1 \mathrm{MHz}$.

In Figure 8 signals at the device outputs are presented. The time diagram and spectrum of the signal at the output of the first device are shown in red, and the output of the second device is in blue. You can see that the timing and spectral diagrams of the signals are identical.

The influence of phase imbalance during the implementation of a phase shift by $\pi / 2$ in the carrier frequency path on the change in the envelope and phase of the phase-modulated components.

Let us consider the effect of phase imbalance during the implementation of a phase shift by $\pi / 2$ in the carrier frequency path on the change in the envelope of the phase-modulated components.

Figure 9a shows on an enlarged scale the envelopes of the phase-modulated components with a phase shift of the phase shifter by $\pi / 2$ in the carrier frequency path by $3^{0}$ - marked in red, $5^{0}-$ marked in blue and $7^{0}-$ marked in purple in the first 
embodiment of the method for optimizing the structure of the spectral effective vector modulation radio signals. In the figure, you can observe the simultaneous manifestation of parasitic amplitude modulation in phase-modulated components.

In the second embodiment of the method for optimizing the structure of spectrally effective radio signals with vector modulation, the phase was shifted by $3^{0}, 5^{0}$, and $7^{0}$ in the first quadrature modulator (Figure 9b), and then an identical shift was performed in the second quadrature modulator (Figure 9c).

Thus, the occurrence of phase imbalance in one of the quadrature modulators does not entail the occurrence of parasitic amplitude modulation in the parallel channel.
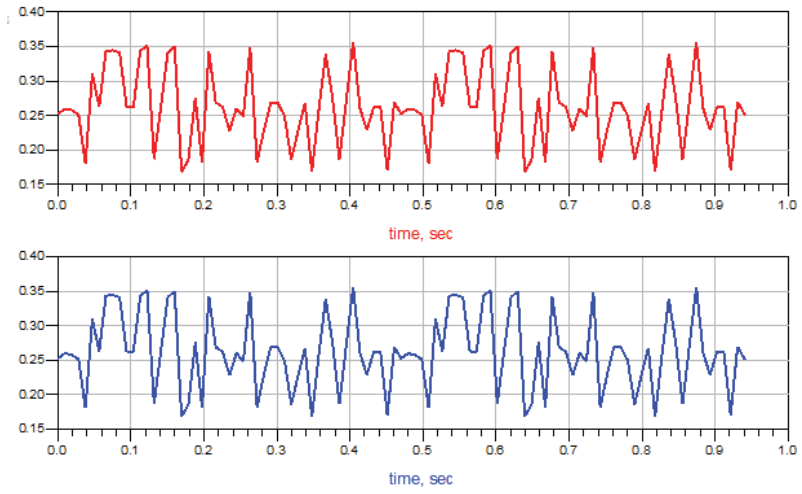

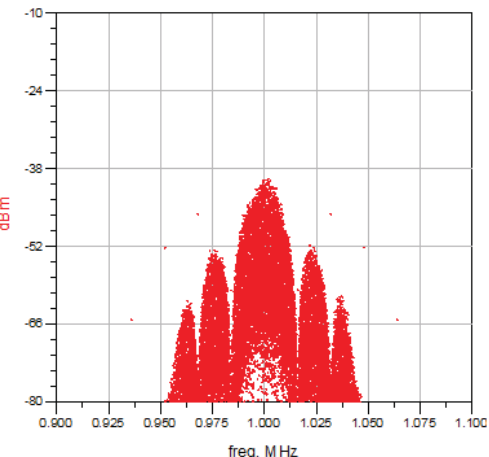

freq, $\mathrm{MHz}$

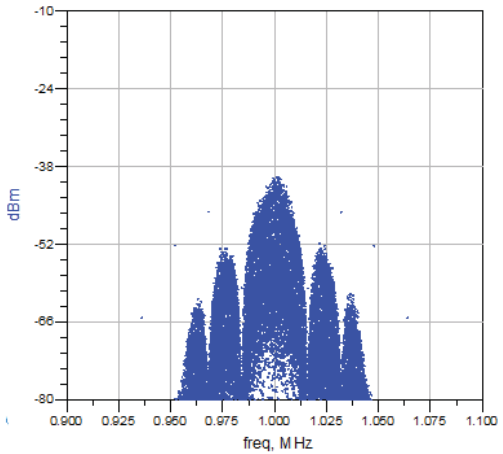

Figure 8. Time and spectral diagrams of the output signal a)

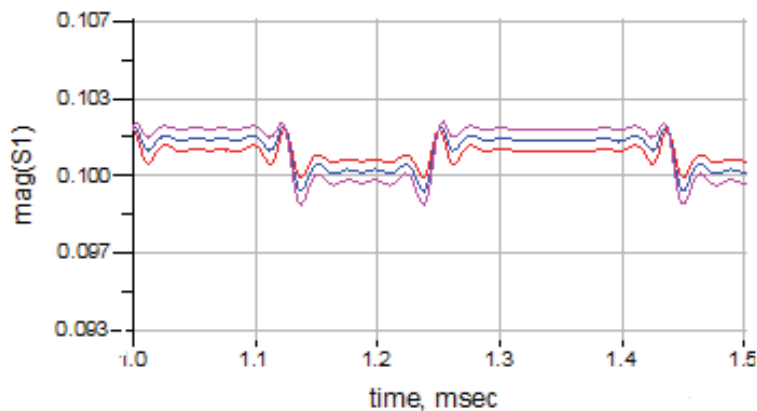

b)

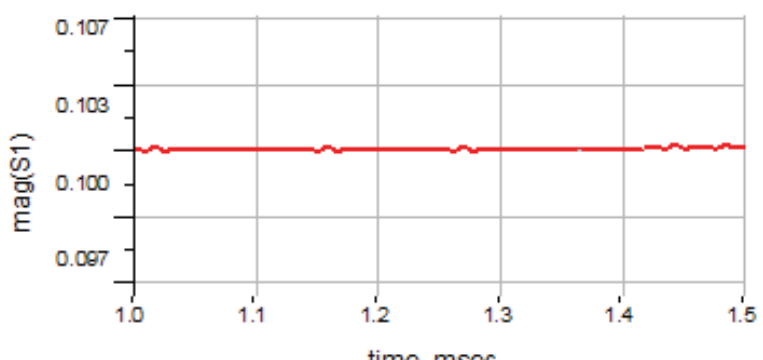

time, msec

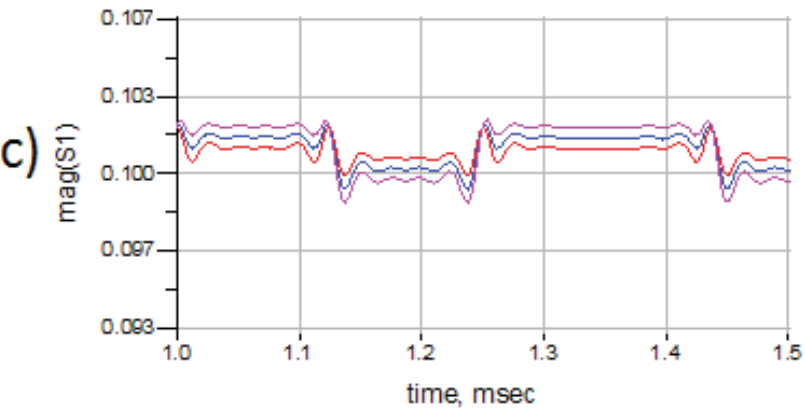

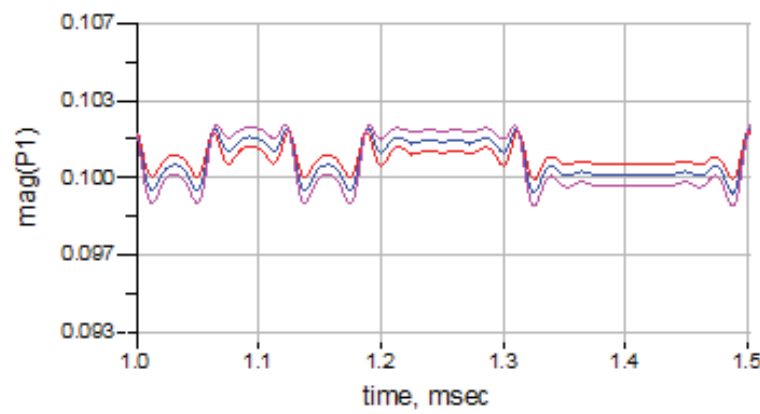
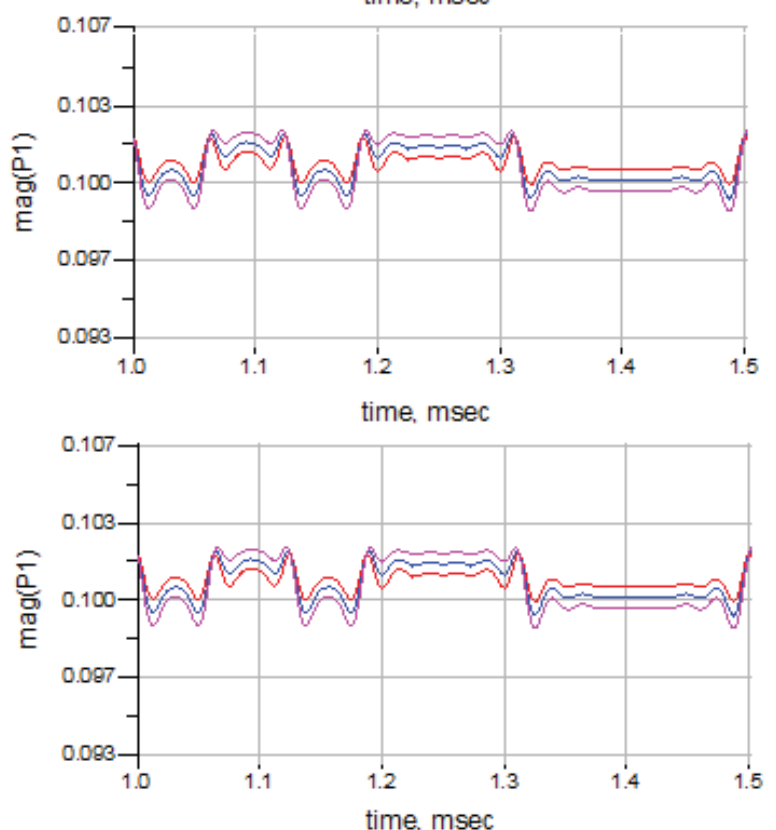

Figure 9. The envelope of the phase-modulated components:

a) phase shift of the phase shifter during the implementation of Figure 1;

b) phase shift in one phase shifter in the implementation of Figre 5;

c) phase shift in two phase shifters in the implementation of Figure 5 
The dependence of the normalized amplitude $U_{n}=A / S$ and the phase $\varphi_{i}$ of the phase-modulated component $u_{i}(t)$ on the phase imbalance during the implementation of the $\pi / 2$ phase shift in the carrier frequency path at different values of the modulating voltage level are shown in Figure 10. The values for the phasemodulated component $u_{q}(t)$ will be identical.

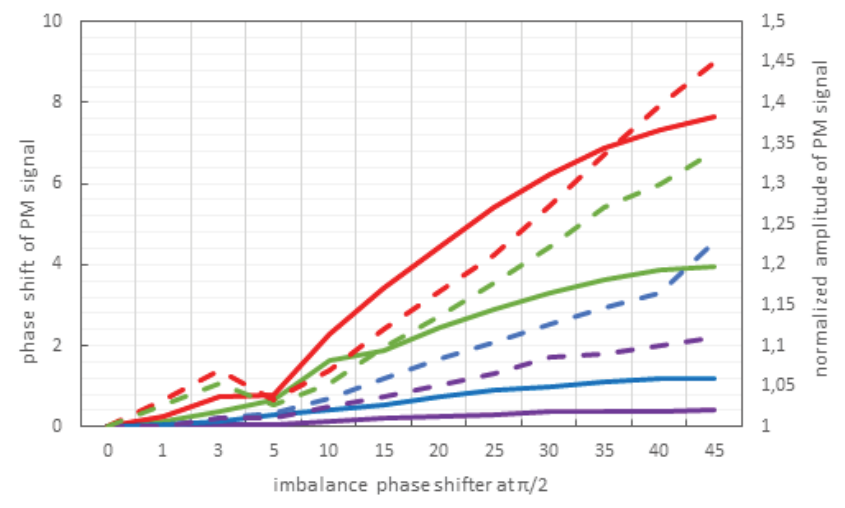

Figure 10. Dependence of the normalized amplitude and phase of the phase-modulated component $u_{i}(t)$ on the phase imbalance during the implementation of the $\pi / 2$ phase shift in the carrier frequency path
In Figure 10, changes in the level of parasitic amplitude modulation are indicated by dashed lines, phase deviations of the phase-modulated component are indicated by solid lines. Rates were calculated at a modulating voltage level corresponding to the phase modulation index $\pi / 18$ - marked in purple, $\pi / 10-$ marked in blue, $\pi / 6$ - marked in green, $\pi / 4$ - marked in red. The phase imbalance during the implementation of the $\pi / 2$ phase shift in the carrier frequency path varied from $0^{0}$ to $45^{\circ}$. It can be observed that with zero phase imbalance when the phase modulation index changes, parasitic amplitude modulation and phase deviations do not occur.

In Figure 11 shows the dependence of the normalized amplitude $U_{H}$ and phase $\varphi_{i}$ of the phase-modulated component $u_{i}(t)$ on the change in the balance modulation coefficient $K_{b m}$ from 1 to 0.7 . The change in the level of parasitic amplitude modulation is indicated by dashed lines, the phase deviation of the phase-modulated component is indicated by solid lines.

The counts were calculated at a modulating voltage level corresponding to the phase modulation index $\pi / 18$ - Figure 11a, $\pi / 10$ - Figure $11 b, \pi / 6$ - Figure $11 c, \pi / 4$ - Figure $11 d$. a)

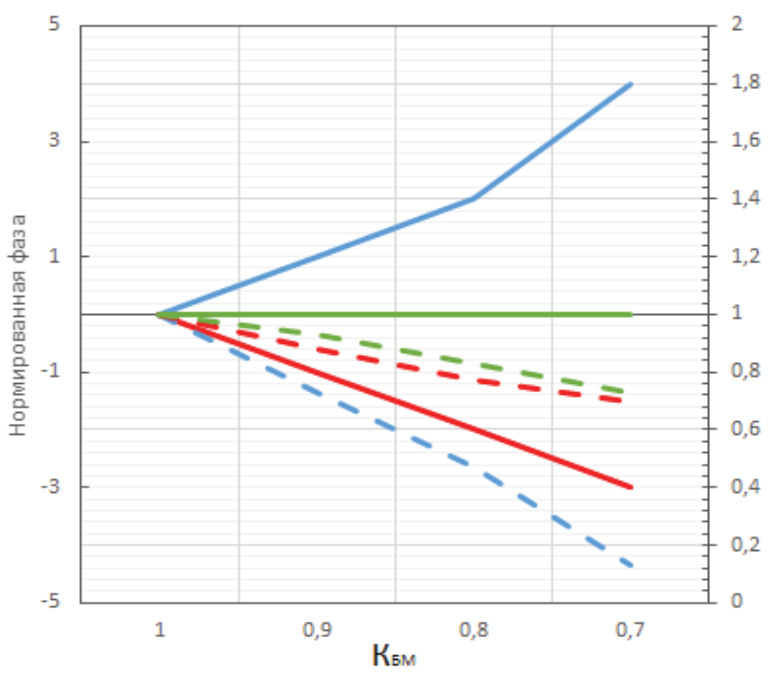

c)

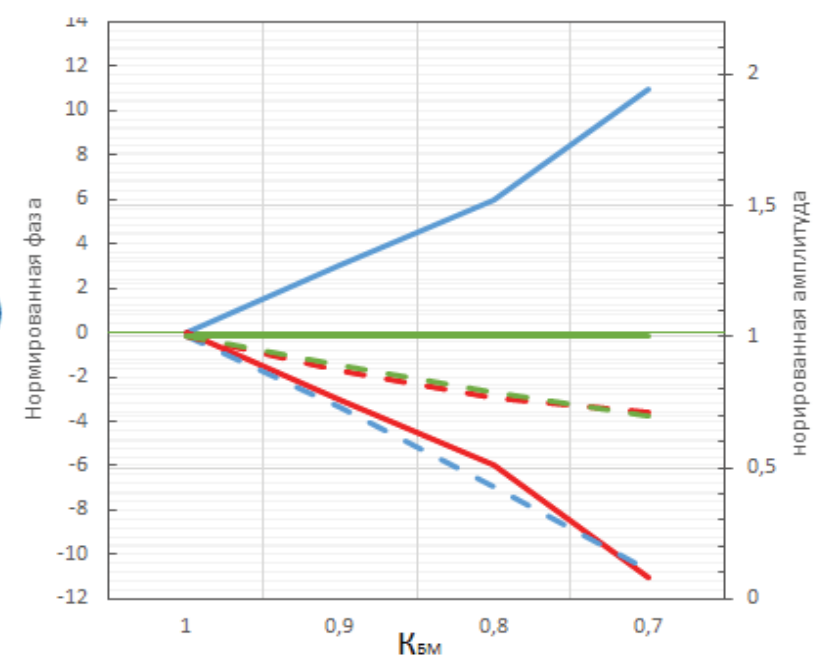

b)
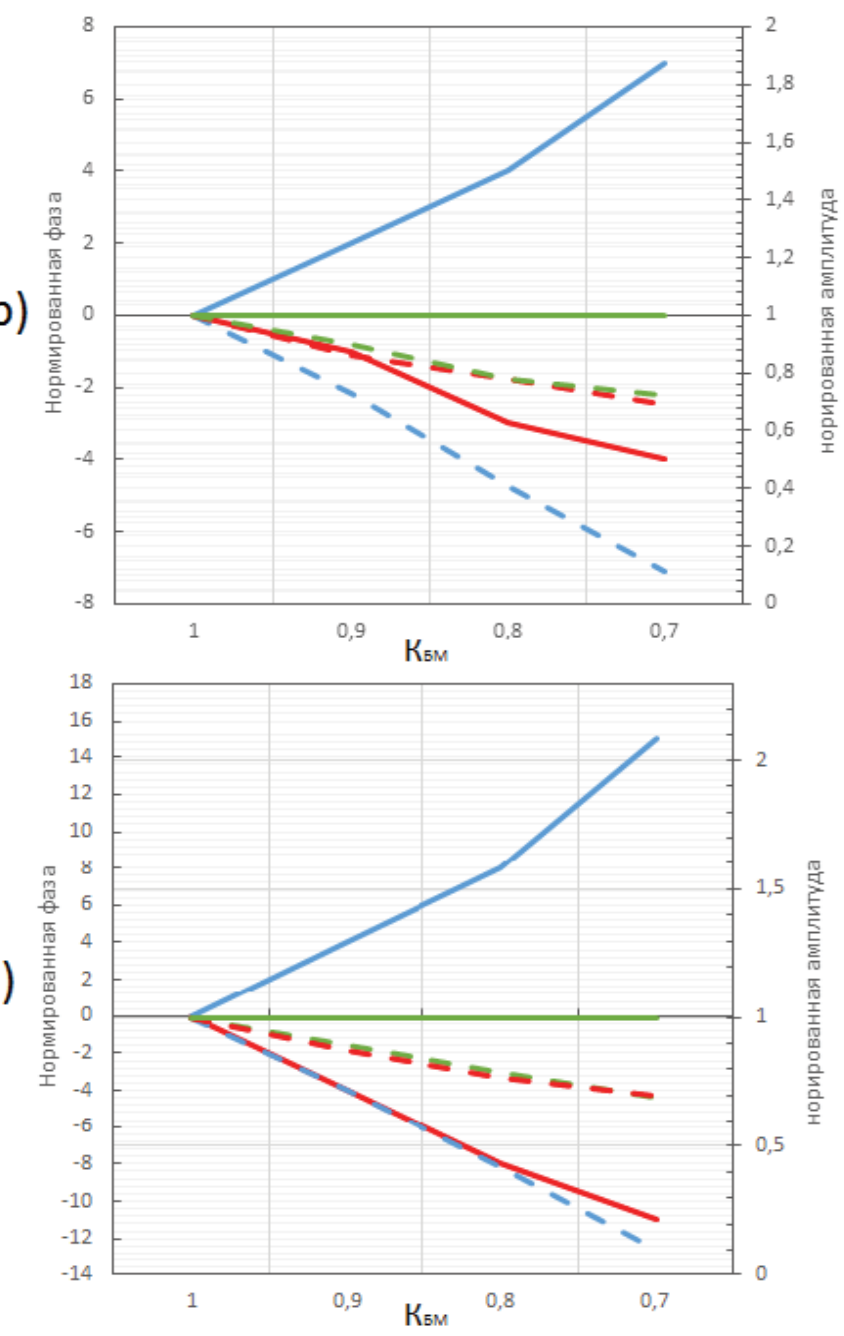

Figure 11. Dependence of the normalized amplitude and phase of the phase-modulated component $u_{i}(t)$ on the change in the balanced modulation coefficient: a) phase modulation index $-\pi / 18$; b) phase modulation index $-\pi / 10$; c) phase modulation index $-\pi / 6$; d) phase modulation index $-\pi / 4$ 


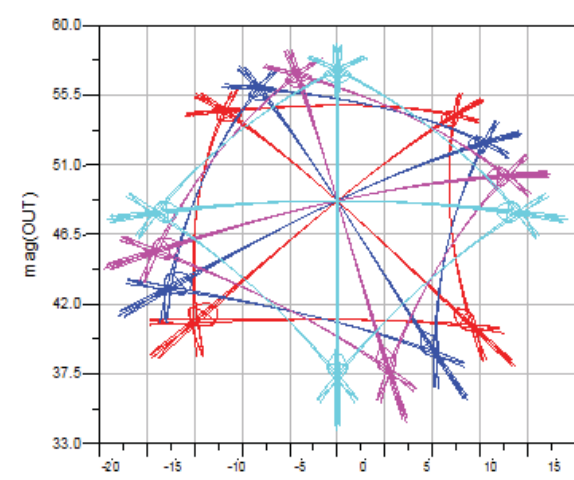

a)

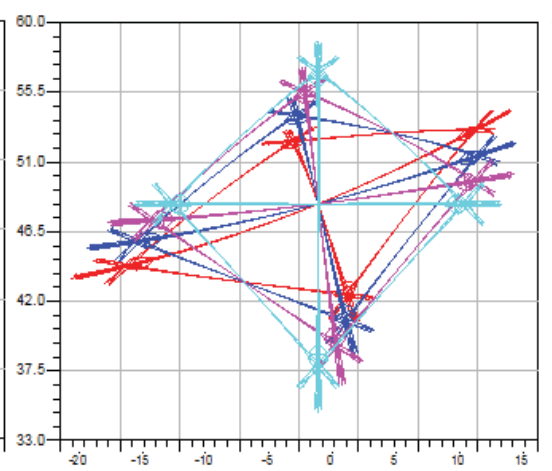

b)

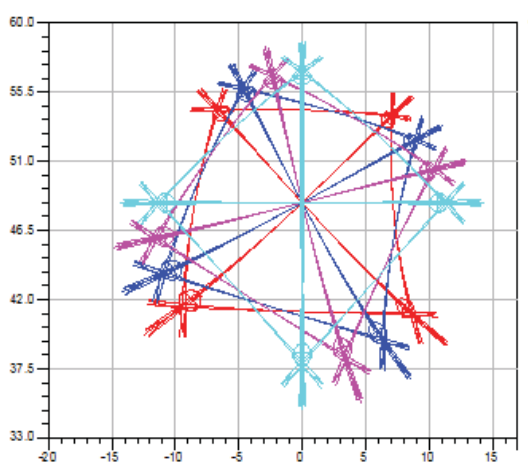

C) phass(OUT)
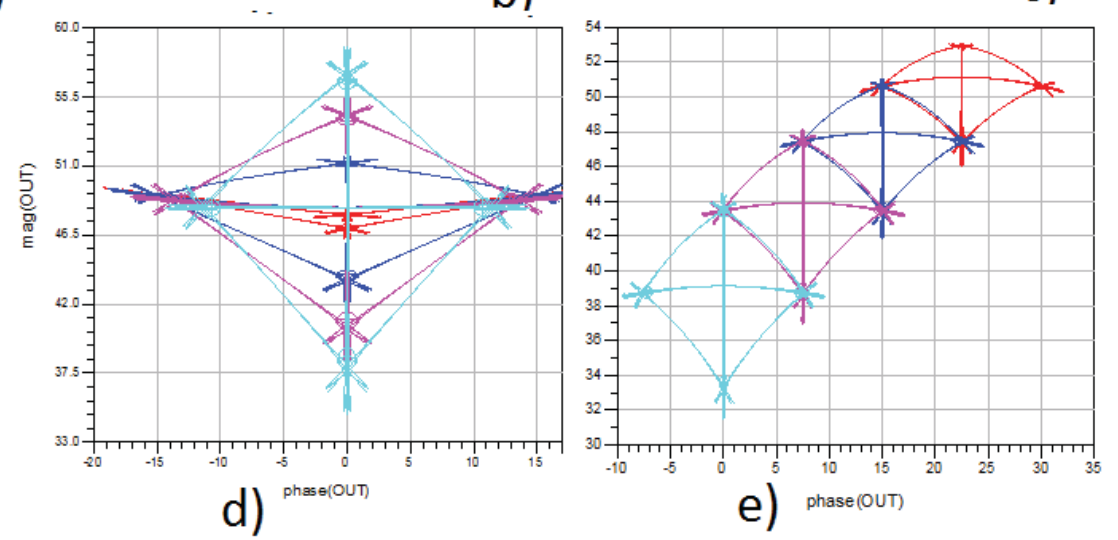

Figure 12. Output signal constellation: a) phase imbalance in the first embodiment of the method; b) phase imbalance in the first quadrature modulator; c) phase imbalance in two quadrature modulators;

d) antiphase imbalance of quadrature modulators; e) phase imbalance in the path of the formation of the quadrature FM component

In Figure 11, parasitic amplitude modulation and phase deviations are indicated in blue when changing $K_{b m 1}$ - a balance modulator that multiplies cosine components, red indicates changes in $K_{b m 2}-$ a balance modulator that multiplies sine components, green colors indicate simultaneous changes $K_{b m 1}=K_{b m 2}$. Obviously, with the balance modulation coefficient $K_{b m 1}=1$, as well as with $K_{b m 1}=K_{b m 2}$, with a change in the phase modulation index, parasitic amplitude modulation and phase deviations do not arise. Influence of phase imbalance during the implementation of the phase shift by $\pi / 2$ in the carrier frequency path on the shape of the output signal constellation.

Let us consider the effect of phase imbalance in the implementation of a phase shift by $\pi / 2$ in the carrier frequency path on the shape of the output signal constellation. For a visual representation, the phase imbalance was introduced $0^{\circ}$ - marked in blue, $15^{\circ}$ - in purple, $30^{\circ}$ - in blue, and $45^{\circ}$ - in red. In Figure 12a shows the effect of phase imbalance in the first embodiment of the method, in Figure 12b, a phase imbalance is carried out in the first quadrature modulator, in Figure 12c, a phase imbalance is implemented in two quadrature modulators, and Figure 12d, the antiphase imbalance of the quadrature modulators is implemented.

As expected in Figure 3, the change in the output signal constellation in the first embodiment of the method corresponds to Figure 12a, and in the second embodiment of the method (Figure 6) corresponds to Figure 12b. The presence of the same phase imbalance in quadrature modulators does not allow to fully compensate for the distortion of the output signal constellation, and the antiphase imbalance introduces even larger images. It can be concluded that when a certain value of the phase imbalance is exceeded, it is impossible to restore the shape of the signal sequence.

In Figure 12e shows the effect of phase imbalance during the implementation of the $\pi / 2$ phase shift in the tract of the formation of the quadrature PM component on the shape of the output signal constellation.

\section{Conclusion}

The obtained results of modeling two variants of the formation of a method for optimizing the structure of spectrally effective radio signals with vector modulation, respectively shown in Figure 1 and Figure 7 show that with the same modulating effect, radio signals are formed that are identical in spectral and temporal forms (Figure 8). In the first embodiment of the method, the occurrence of a phase imbalance when the phase shift by $\pi / 2$ in the carrier frequency path leads to the simultaneous manifestation of parasitic amplitude modulation in the phase-modulated components. In the second embodiment of the method, the occurrence of phase imbalance in one of the quadrature modulators does not entail the occurrence of parasitic amplitude modulation in the parallel channel.

With zero phase imbalance, as well as with a balanced modulation coefficient of $K_{b m}=1$ and $K_{b m 1}=K_{b m 2}$, a change in the phase modulation index does not entail the appearance of parasitic amplitude modulation and phase deviation. The occurrence of phase imbalance during the implementation of a phase shift by $\pi / 2$ in the carrier path, as well as phase imbalance in one or simultaneously two quadrature modulators, to varying degrees, affect the shape of the output signal constellation. 


\section{References}

1. L.A. Belov. (2020). Intermodulation distortion of ultra-high frequency signals. Moscow: Hotline - Telecom 2020. 144 p.

2. System and method of linearization of the power amplifier: Pat. 2433522 Rus. Federation. IPC H03F 1/32 / V.Ya. Arkhipenkov, S.A. Goreinov, A.O. Melnikov; No. 2010115827; declared 04/21/10; publ. 10.11.11, Bul. No. 31-22 p.

3. S.A. Sherstyukov, S.S. Pechnikov. (2020) Optimization of the structure of spectrally efficient radio signals on the basis of functional converters and vector modules as part of the predistortion path. Systems for the formation, formation and processing of signals. Vol. 11. No. 2, pp. 4-10.

4. P.A. Popov, S.A. Sherstyukov, D.A. Zhaivoronok, V.V. Romashov. (2001). Quadrature radio signal conditioners. Voronezh: Voronezh Institute of the Ministry of Internal Affairs of Russia. $176 \mathrm{p}$.

5. S.A. Sherstyukov. (2010). Functional converters of modulating voltage in quadrature RF signal conditioners with angle modulation. Voronezh: Scientific book. 207 p.
6. S. S. Pechnikov, S. A. Sherstukov. (2020). Optimization of the structure of spectrally efficient radio signals based on functional converters and vector modulators as part of the predistortion path, 2020 Systems for synchronization, generation and processing of signals in telecommunications (SINCHROINFO), Svetlogorsk, Russia, p. 1-5, DOI: 10.1109/SYNCHROINFO 49631.2020.9166070.

7. M.K. Da Savila. Vector Locked Loop, U.S. Patent 5,105,168, April 14, 1992.

8. D. Cox, Linear Amplification with Nonlinear Components, in IEEE Transactions on Communications, vol. 22, no. 12, pp. 1942-1945, December 1974, doi: 10.1109/TCOM.1974.1092141.

9. A.A. Kurushin. (2005). Modeling of digital streams of radio communication in the ADS environment / Ptolemy. Moscow: Solon-Press. $184 \mathrm{p}$.

10. K. Feer (200) Wireless digital communication. Modulation and assortment expansion methods. Moscow: Radio and communication. $520 \mathrm{p}$.

\section{АНАЛИЗ ПАРАМЕТРИЧЕСКОЙ ЧУВСТВИТЕЛЬНОСТИ СПОСОБА ОПТИМИЗАЦИИ СТРУКТУРЫ СПЕКТРАЛЬНО-ЭФФЕКТИВНЫХ РАДИОСИГНАЛОВ}

Печников Сергей Сергеевич, Воронежский институт МВД России, Воронеж, Россия, orl_os@mail.ru Шерстюков Сергей Анатольевич, Воронежский институт МВД России, Воронеж, Россия, sherstukov@vimvd.ru

\section{Аннотация}

В настоящее время является актуальным вопрос повышения скорости передачи информации в беспроводных сетях связи. Растущий спрос на спектральную эффективность в системах радиосвязи порождает необходимость внедрения сигналов с амплитудно-фазовой модуляцией, которые можно реализовать в многоуровневых линейных схемах. Несмотря на все свои преимущества сигналам с векторной модуляцией свойственно изменение огибающей, что делает не возможным применение высокоэффективных нелинейных усилителей мощности. Эффективность энергопотребления, безусловно, является критически важным фактором для портативных систем радиосвязи, где часто используются источники питания в небольших корпусах, а наличие энергопотерь при теплоотдаче является существенным недостатком, требующим дополнительных систем охлаждения. В связи с чем, при разработке современных средств радиосвязи, перед радиоинженерами стоит противоречивая задача достижения максимальной энергетической и спектральной эффективности. Одним из подходов по снижению нелинейных искажений, возникающих в результате усиления сигналов с векторной модуляцией в нелинейных усилителях мощности является применение схем линеаризации. Данная работа посвящена вопросу повышения энергетической и спектральной эффективности сигналов с амплитудно-фазовой модуляцией. Рассмотрены ограничения, накладываемые на входные сигналы при применении способа оптимизации структуры спектрально-эффективных радиосигналов с векторной модуляции, рассмотрено формирование выходного сигнала, влияние дисбаланса фазы фазовращателей на $\pi / 2$, влияние коэффициента балансной модуляции, проведен анализ параметрической чувствительности. Рассмотрена возможность применения квадратурных модуляторов для формировании составляющих с фазовой модуляцией и постоянной огибающей. Произведено моделирование данного способа и выявлены влияние дисбаланса фазы на форму выходного сигнального созвездия.

Ключевые слова: цифровая радиосвязь, сигналы с высокой спектральной эффективностью, линеаризация усилителей мощности, фазовый дисбаланс, постоянная огибающая.

\section{Литература}

І. Белов Л.А. Интермодуляционные искажения сигналов сверх высоких частот. Уч. пособие для вузов. М.: Горячая линия - Телеком, 2020. 144 с.

2. Система и способ линеаризации усилителя мощности: Пат. 2433522 Рос. Федерация. МПК Н03F I/32 / В.Я. Архипенков, С.А. Горейнов, А.О. Мельников; № 2010II5827; заявл. 21.04.10; опубл. 10.1І.ІІ, Бюл. № 31.22 с.

3. Шерстюков С.А., Печников С.С. Оптимизация структуры спектрально-эффективных радиосигналов на базе функциональных преобразователей и векторных модуляторов в составе тракта предыскажения // Системы синхронизации, формирования и обработки сигналов. 2020. Т. II. № 2. С. 4-І0. 4. Попов П.А., Шерстюков С.А., Жайворонок Д.А., Ромашов В.В. Квадратурные формирователи радиосигналов. Монография. Воронеж: Воронежский институт МВД России, 200I. 176 с.

5. Шерстюков С.А. Функциональные преобразователи модулирующего напряжения в квадратурных формирователях радиосигналов с угловой модуляцией. Монография. Воронеж: Научная книга, 2010. 207 с.

6. Pechnikov S.S., Sherstukov S.A. Optimization of the Structure of Spectral-Effective Radio Signals on the Basis of Functional Converters and Vector Modulators in the Composition of the Predistortion Tract // 2020 Systems of Signal Synchronization, Generating and Processing in Telecommunications (SYNCHROINFO), Svetlogorsk, Russia, 2020, pp. I-5, doi: I0.II 09/SYNCHROINFO4963I.2020.9166070.

7. Da Savila M.K., Vector Locked Loop, U.S. Patent 5, 105, I68, April I4, 1992.

8. Курушин А.А. Моделирование цифровых потоков радиосвязи в среде ADS / Ptolemy. М.: Солон-Пресс, 2005. 184 с.

9. Феер К. Беспроводная цифровая связь. Методы модуляции и расширения спектра. Пер. с англ. Под ред. В.И. Журавлева. М.: Радио и связь, 2000. $520 \mathrm{c.}$

Информация об авторах:

Печников Сергей Сергеевич, адъюнкт. Воронежский институт МВД России, Воронеж, Россия

Шерстюков Сергей Анатольевич, профессор кафедры инфокоммуникационных систем и технологий,д.т.н., доцент, Воронежский институт

МВД России, Воронеж, Россия 